\title{
CORRIGENDUM
}

\section{The Knowledge Gap in World Politics: Assessing the Sources of Citizen Awareness of the United Nations Security Council - CORRIGENDUM}

\section{Lisa Maria Dellmuth}

doi: 10.1017/S0260210515000467, published online by Cambridge University Press 11 January 2016.

In the above published article, there is an error in Hypothesis 3 on page 10. This Hypothesis should read correctly as "People with a cosmopolitan identity are more likely to be more aware of IOs."

\section{Reference}

Dellmuth, Lisa Maria, 'The Knowledge Gap in World Politics: Assessing the Sources of Citizen Awareness of the United Nations Security Council', Review of International Studies, published online 11 January 2016 doi:10.1017/S0260210515000467. 